A History of Colonial Medical Education in the Province of New York, with its Subsequent Development (1767-1830)

Byron Stookey, A.M., M.D., SC.D. Pp. xix +286 , illustrated. Springfield, Illinois: Charles C Thomas. 1962. \$10.50.

This is an account of the founding of America's first medical faculty, King's College, later to become Columbia. The work is scholarly and restrained, written in clear, firm prose, with no frill or purple passage. The picture that emerges is a serious one of detailed brushwork, with an unobtrusive background of American history. Apart from personalities and medical politics, which form the heart of the book, there are sidelights on the examination systems in vogue, an appendix on the syllabuses for the various courses of study and many other incidental pieces of information.

The whole book has the stamp of that thoroughness we have come to associate with American scholarship: use of original sources, detailed bibliography and excellent index. Added to these are numerous carefully selected illustrations. It is a pleasant, informative book.

\section{Slit-Lamp Gonioscopy}

George Gorin, M.D., and Adolph Posner, M.D. Second edition. Pp. $209+$ xiv, illustrated. Baltimore: Williams and Wilkins. London: Baillière, Tindall and Cox. 196r. 6os.

This textbook on gonioscopy discusses the techniques of examination of the angle of the anterior chamber of the eye.

There are chapters on the anatomy, comparative anatomy, embryology and history of gonioscopy. This is followed by the technique of examination and the interpretation of gonioscopic findings in normal eyes and in the different types of glaucoma. It then reviews the value of this diagnostic method in inflammations, injuries and tumours of the anterior segment of the eye.

The first edition of this book appeared in 1957 and this edition has been brought up to date and includes a chapter on goniophotography.

The chief value of gonioscopy lies in the classification of glaucoma. It enables one to differentiate chronic simple glaucoma from angle closure glaucoma.

The value of the procedure may have been exaggerated in that an angle may appear gonioscopically closed and the eye has a normal tension. As the authors point out, the procedure must therefore be used in conjunction with other glaucoma tests.

The book is clearly written, with many new illustrations, and there is a useful bibliography and glossary. This comprehensive manual of gonioscopy is a valuable addition to the ophthalmologist's library.

\section{Fat Embolism}

Simon SevitT. Pp. $x+233$, illustrated. London: Butterworths. 1962. $60 s$.

In producing the first book in the English language on fat embolism Dr. Sevitt has marked the centenary of the original papers on the subject by Zenker and Wagner in a most fitting manner. He has produced a book which will be a standard work for many years to come-a book which no one who has any interest in the subject can afford to be without, be he pathologist surgeon or student.

Every aspect of the subject is considered. The@ historical background, ætiology, pathogenesis, clinicalsignificance, symptomatology, prognosis, therapy and medico-legal aspects are each dealt with carefully ands exhaustively. Every significant reference is quoted and critically appraised, the facts are placed in perspective the arguments for and against each theory discussed and then the conclusions are drawn in the light of the author's own extensive experience during is years as pathologist to the Birmingham Accident Hospital.

It is difficult to pick out one section of the book ass better than any other, but such points as the discussion on the validity of the chemical-toxic theory of action of fat emboli are a delight to read and a model of lucid thought and scientific argument.

The illustrations, mainly photomicrographs, areo plentiful, helpful and clear. There is a full list of references at the end of each chapter and a good index This valuable book is full of information and written in a simple readable style. It should be read by all who have an interest in the subject.

The Year Book of Medicine (1962-1963 Year Book $\frac{\dot{\omega}}{\delta}$
Series).

Edited by P. B. Beeson and others. Pp. 7359 illustrated. Chicago: Year Book Medical Publishers. London: Lloyd Luke. 1962. 6os.

This book presents a digest of recent clinical and experimental medical literature published in 1961 and early 1962. In many instances pertinent editorial col-e ments are added parenthetically and this considerały heightens the interest in the subject presentation. The summaries have been prepared in a clear and conclese manner and the book should be of interest to the busyz clinician, who is endeavouring to keep abreast of the broad advances being made in medicine as a whole, as well as thei clinical research worker. It is essentially a reference book although it cannot claim to be entirely comprehensive; 0 for example literature other than from the United $=$ States or Great Britain is virtually ignored. In addition it should not be assumed that reading any particular? account can be a satisfactory substitute for consulting the actual paper. An example of this need for caution is a paper on the myasthenic syndrome in bronchial cancer for the data provided in the summary do not do 3 justice to the important electrodiagnostic information in the original.

The use of editorial criticism, mentioned above, could be extended to advantage, for its absence shouldô not be taken to imply that the paper summarised was 3 beyond reproach. Thus one sub-section is headedo 'Asthma; Farmer's Lung' which together with the paperon the latter subject must inevitably convey the impress- $\rightarrow$ ion that these conditions are related. Most workers in this field would agree that such a conclusion is unwarranted and therefore this paper should not have $N$ gone uncriticised.

These reservations are not designed to detract from 0 the general merit of volume and it is warmly commended to all interested in internal medicine for the amazingo amount of well-presented information packed into com ${ }^{-}$ paratively few pages. 